\title{
OPTIMIZATION OF METHODOLOGY TO ANALYZE ASCORBIC AND DEHYDROASCORBIC ACID IN VEGETABLES
}

Flávia Milagres Campos*, Sônia Machado Rocha Ribeiro, Ceres M. Della Lucia e Helena Maria Pinheiro-Sant'Ana

Departamento de Nutrição e Saúde, Universidade Federal de Viçosa, Av. PH Rolfs, s/n, 36571-000 Viçosa - MG, Brasil

Paulo César Stringheta

Departamento de Tecnologia de Alimentos, Universidade Federal de Viçosa, Av. PH Rolfs, s/n, 36571-000 Viçosa - MG, Brasil

Recebido em 10/1/08; aceito em 18/8/08; publicado na web em 15/12/08

\begin{abstract}
In this study, different solutions to extract vitamin $\mathrm{C}$ were tested. High-performance liquid chromatography was chosen and the conditions were based on isocratic elution in reverse phase column. Dehydroascorbic acid was determined indirectly after its reduction using dithiothreitol. The use of metaphosphoric acid to stabilize the vitamin $\mathrm{C}$ was shown to be required and it was necessary to neutralize the $\mathrm{pH}$ of the extract to apply dithiothreitol. The average recovery was $90 \%$ in collard and tomato samples. The presence of oil did not interfere in extraction and the methodology can be used to analyze stir fried vegetables.
\end{abstract}

Keywords: vitamin C; extraction; chromatography.

\section{INTRODUCTION}

Vitamin $\mathrm{C}$ has received most attention from researchers, mainly because of its antioxidant action. Vitamin $\mathrm{C}$ is necessary to produce collagen, and is essential for phenylalanine and tyrosine oxidation and to convert pholacine to tetra-hydrophilic acid, and is also involved in the inflammatory reaction process. ${ }^{1,2}$ Furthermore, it is known the importance of vitamin $\mathrm{C}$ in the bioavailability of dietetic non-heminic iron. ${ }^{3}$

The major active form of the vitamin is ascorbic acid (AA) but its oxidized form, dehydroascorbic acid (DHA) also shows biological function. ${ }^{4}$ However, human beings cannot synthesize AA, which needs to be supplied through food. ${ }^{1}$ Vegetables and fruits are known to be the best sources of vitamin $\mathrm{C}$ and it is important to determine their AA and DHA contents. Obtaining reliable data regarding the vitamin $\mathrm{C}$ contents in vegetables has become imperative in the light of epidemiological studies that relate vegetable ingestion and disease prevention.

Vitamin C analysis in foods requires care that can vary depending on the plant matrix under study. Cell structure disruption during the extraction processes allows enzymes responsible for AA degradation to come into contact with the substrate. Therefore it may be necessary to prevent the enzymatic action by reducing the $\mathrm{pH}$, what favors AA stability. Furthermore, the presence of metals such as iron and copper increase AA oxidation ${ }^{1}$ and a metal chelating agent is usually recommended..$^{5}$

Pure water ${ }^{6}$ or acid solutions have been used to extract AA from plant tissues. The acids commonly used include metaphosphoric acid (MPA) $)^{5,7-10}$ and oxalic acid ${ }^{5,11,12}$ alone or in combinations with other acids and/or organic solvents, added or not of antioxidants such as EDTA and BHT.

Different analysis methods have been reported for vitamin $\mathrm{C}$ in foods. The classic method is the titulometric that does not quantify DHA but only AA. ${ }^{13}$ Spectrophotometry, ${ }^{14}$ fluorimetry, ${ }^{10,15}$ amperometry, ${ }^{16}$ electrophoresis, ${ }^{17,18}$ chromatography ${ }^{7-9,19}$ and enzymatic methods ${ }^{20}$ have also been used, but some of these methods have limitations regarding specificity. High-performance liquid chroma-

*e-mail: flaviamilagrescampos@yahoo.com.br tography (HPLC) stands out as a reliable and usually simple method. After separation in chromatography column, the use of a diode array detector can improve the reliability of AA identification. ${ }^{19}$ As DHA detection is hindered by its weak molar absortivity, ${ }^{1}$ most researchers choose to reduce it to AA before chromatographic separation, making indirect quantification by difference. Among the reducing agents dithiothreitol (DTT) has been widely used. ${ }^{6,19,21,22}$

The objective of this study was to test the methodology for analyzing AA and DHA in vegetables by reverse phase high performance liquid chromatography, optimizing the extraction processes of ascorbic acid and DHA conversion to ascorbic acid, using dithiothreitol (DTT). In addition, the efficiency of the optimized methodology was verified in vegetables with the addition of oil.

\section{EXPERIMENTAL}

\section{Material and sample preparation}

The vegetables chosen for this study were collards (Brassica oleracea, var. acephala), Manteiga cultivar and tomato (Lycopersicum esculentum), Santa Cruz variety, because they are widely consumed in Brazil and are very different in their structure, that allowed assessment of the efficiency of the extraction method and analysis of two different types of plants.

The vegetables were purchased at a suitable degree of development: tomatoes with uniform red coloring and collard leaves at standard commercial size.

The following experiment was carried out to test the application of the method on stir fried vegetables and the interaction with oil: collard leaves were washed in running water, dried on paper towel, divided down the middle and chopped. One of the halves has vitamin $\mathrm{C}$ extracted right after chopping. Soybean oil was added to the other half, in the proportion of $7 \mathrm{~g}$ oil to $50 \mathrm{~g}$ collards. The sample with oil was submitted to the extraction process.

\section{Reagents and other materials}

The following were used: ultra pure water, produced in a MilliQ system (Millipore, USA), metaphosphoric acid (p.a.) (Merck, 
Germany), dithiothreitol (DTT) (Sigma Aldrich, Germany), sulfuric acid $\left(\mathrm{H}_{2} \mathrm{SO}_{4}\right)$ (p.a.) (Mallinckrodt, USA), standard L-ascorbic acid and acetic acid (HPLC grade, Brazil).

The samples were filtered through filter paper (Quanty, Brazil) and before injection the samples were filtered in polyethylene 0.45 $\mu \mathrm{m}$ porosity Millex HV filtering units (Millipore, Brazil).

\section{Vitamin C extraction}

The vitamin C extraction methods were tested using the following extracting solutions: only water, as proposed by Gökmen et al., ${ }^{6} 4.5 \%$ metaphosphoric acid (MPA) according to the method proposed by Giannakourou et al. ${ }^{9}$ and extracting solution consisting of 3\% MPA, $8 \%$ acetic acid, $1 \mathrm{mM}$ EDTA and $0.15 \mathrm{M} \mathrm{H}_{2} \mathrm{SO}_{4}$, based on Franke et $a l .{ }^{8}$ with some modifications.

The extraction processes had the following sequence and only the extracting solutions were altered: the vegetables were washed in running water and the inedible parts were removed. Fifteen $\mathrm{mL}$ of the extracting solution were added to $5 \mathrm{~g}$ sample; next the sample was ground in a micro triturator for $5 \mathrm{~min}$ and filtered under vacuum through filter paper. The filtrates were diluted in water to the volume of $25 \mathrm{~mL}$ and centrifuged for $15 \mathrm{~min}$ at $2683 \mathrm{xg}$ (4000 rpm). The supernatant was stored at $5{ }^{\circ} \mathrm{C}$ until the chromatography analysis that was performed on the same day.

It is emphasized that the samples were kept out of sunlight and artificial light throughout the analysis period by using amber glassware or aluminum paper.

\section{DHA reduction}

DHA was quantified by difference between the total AA content (after DHA reduction to AA) and the AA contents before the DHA conversion.

DTT was used as DHA reducing agent. Four different DTT concentrations were tested. The following solutions were added to $1 \mathrm{~mL}$ of the sample extract: $1 \mathrm{~mL}$ DTT solution at 4, 8, 10 and 50 $\mathrm{mM}$ and $1 \mathrm{~mL}$ DTT solution at 10 and $50 \mathrm{mM}$, with the addition of $0.5 \mathrm{~mL}$ Trizma buffer ( $\mathrm{pH}$ 9.0). The buffer was added to raise the $\mathrm{pH}$ during the reaction time to around 5.5.

During the reaction the solutions were kept at room temperature, sheltered from light, for periods between 10 and $120 \mathrm{~min}$.

The addition of $0.4 \mathrm{M}$ sulfuric acid was also tested to reduce the $\mathrm{pH}$ in the solution before the chromatographic injection.

\section{Chromatographic conditions}

Two chromatographic conditions were tested. One, outlined by Giannakourou et al..$^{9}$ consisted of an isocratic elution, detection in the UV range, using a mobile phase of ultra pure water with $\mathrm{pH}$ adjusted to 2.2 with MPA, at a flow rate of a $1 \mathrm{~mL} / \mathrm{min}$. The mobile phase proposed by Franke et al. ${ }^{8}$ was also tested, with alteration in the buffering agent: $1 \mathrm{mM}$ monobasic sodium phosphate ( $\left.\mathrm{NaH}_{2} \mathrm{PO} 4\right)$ and $1 \mathrm{mM}$ EDTA, $\mathrm{pH}$ adjusted to 3.0 with phosphoric acid $\left(\mathrm{H}_{3} \mathrm{PO}_{4}\right)$, $1 \mathrm{~mL} / \mathrm{min}$ flow, isocratic elution and detection at $245 \mathrm{~nm}$. In both the conditions a Lichospher $100 \mathrm{RP} 18,250 \mathrm{~mm}$ x 4 mm, $5 \mu \mathrm{m}$ column was used (Merck, Germany). A high-performance liquid chromatography system, Shimadzu, equipped with a high pressure pump, model LC10AT VP; automatic injector with a $50 \mu \mathrm{L}$ loop, model SIL-10AF; a UV-visible diode array detector model SPD-M10A; controlled by the Multi System software, Class VP 6.12, was used for the analysis.

The AA in the samples was quantified by the calibration curve. The standard stock solution ( $1 \mathrm{mg} / \mathrm{mL} \mathrm{AA})$ was prepared in ultra pure water and solutions of various concentrations were prepared by diluting the stock solution in extracting solution. New standard solutions were prepared daily. The real concentration of the solutions was calculated from the following equation:

$\mathrm{C}(\mu \mathrm{g} / \mathrm{mL})=\mathrm{ABS} \times 10^{4} / \mathrm{E}^{1 \%}{ }_{1 \mathrm{~cm}}$

where $\mathrm{C}$ was the real concentration, $\mathrm{ABS}$ was the maximum absorptivity (read at $245 \mathrm{~nm}$ ) in phosphate buffer solution, $\mathrm{pH} 2.0$ and $\mathrm{E}^{1 \%}{ }_{1 \mathrm{~cm}}$ was the coefficient of molar absorptivity (560). ${ }^{1}$

\section{RESULTS AND DISCUSSION}

\section{Optimization of the extraction and chromatography analysis of vitamin $\mathbf{C}$}

The extraction of vitamin $\mathrm{C}$ from collards using only water was shown conclusively to be inefficient because the amount of AA detected was about 30 times less than the quantity detected when the samples were extracted with a 4.5\% MPA solution; shown in Figure 1. Similarly, the extraction from the tomato samples with water did not give good results, and the AA content in the extracts of the samples extracted with MPA solution was about $40 \%$ greater than the samples extracted with pure water. These results are in line with the report by Franke et al. ${ }^{8}$ in a study that quantified AA in fruits and vegetables. According to the authors, extracting AA with water alone was sufficient when dealing with fruit, but the adoption of this method for leafy vegetables were shown to cause AA loss during the extraction process, especially from lettuce, whose AA peak was not even detected. The AA may have been degraded during extraction with water, or the extraction may have been incomplete, because of the differences inherent to vegetables. In the present study, the degradation or inefficiency in AA extraction during use of pure water was clearly shown for collards. Although AA loss during extraction with water was less in the tomato, the loss was quite considerable.

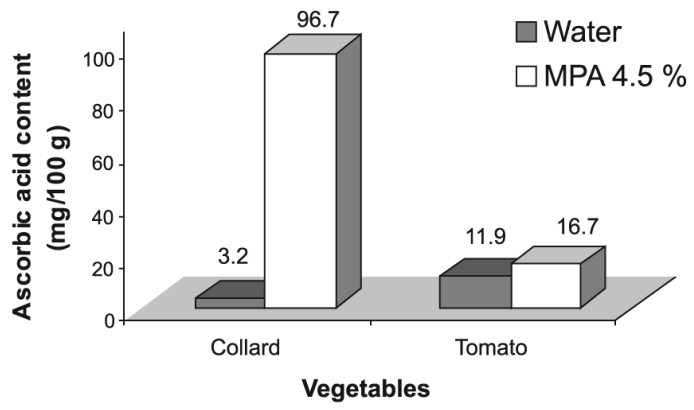

Figure 1. Ascorbic acid contents $(\mathrm{mg} / 100 \mathrm{~g})$ in collards and tomato. Water: extracting solution consisting of pure water. $4.5 \%$ MPA: extracting solution consisting of $4.5 \%$ metaphosphoric acid

Further according to Franke et al., ${ }^{8}$ it can be assumed during extraction with water that the ascorbate oxidase enzyme, present in leafy vegetables, was not completely inactivated. The optimum $\mathrm{pH}$ range of reaction of the enzyme is between 5.0 and 6.5. ${ }^{23}$ The $\mathrm{pH}$ ranged from 5.7 to 6.1 in the collard extracts without addition of MPA, while in the extracts that contained MPA the $\mathrm{pH}$ was always below 2.0. It is probable that in the solutions containing 4.5\% MPA the ascorbate oxidase was inactivated, because at $\mathrm{pH}$ below 4 its activity is practically zero. When extraction with water in collards and tomato was compared, the AA degradation might have been greater in the collards samples because the $\mathrm{pH}$ of the extracts was in the 
optimum range of ascorbate oxidase action. In the tomato extracts, as the $\mathrm{pH}$ was 4.4 , because of the acidity of the tomato itself, the enzyme acted less efficiently and AA degradation was consequently smaller. Ascorbate oxidase is indicated as the main enzyme involved in AA enzymatic degradation. ${ }^{4}$

However, it was observed that using 4.5\% MPA as extracting solution and a mobile phase consisting of ultra pure water, $\mathrm{pH} 2.2$ adjusted with MPA, for several weeks, there was a loss of quality in the data, with the appearance of double peaks for AA and loss of quality in the resolution (Figure 2A). This situation may have arisen because of the accumulation of MPA crystals in the chromatography column, with consequent alteration in AA protonation during the passage through the column, because a high concentration of hydrogen ions maintains AA completely protonated. ${ }^{2}$ Other authors have reported problems in the use of MPA. Iwase ${ }^{24}$ reported difficulty in dissolving MPA in ionized water and problems when weighing MPA caused by its hygroscopic quality.
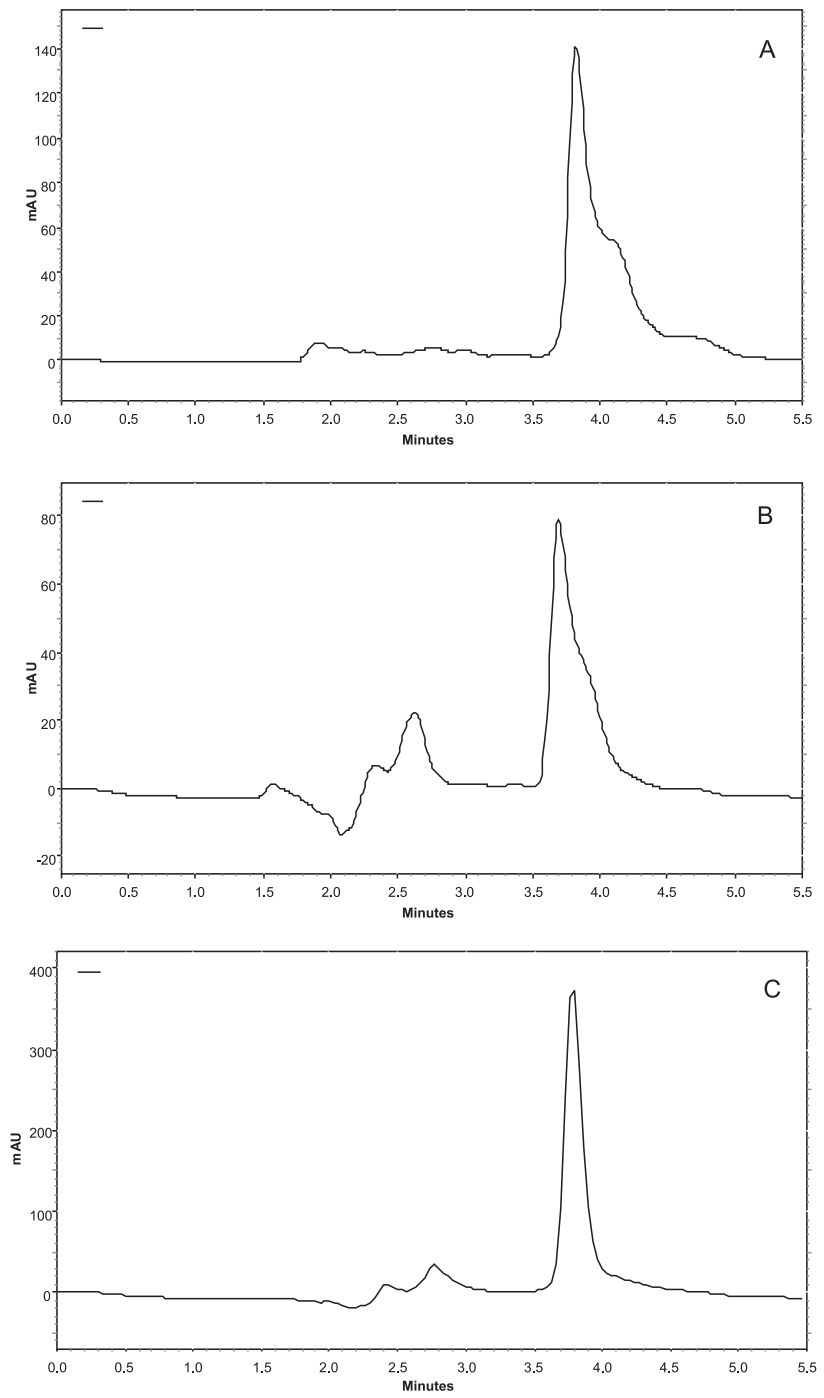

Figure 2. Chromatography of tomato samples (A) 4.5\% MPA, mobile phase acidified water, $p H 2.2$ with MPA; (B) extracting solution $3 \%$ MPA, mobile phase $1 \mathrm{mM} \mathrm{NaH}_{2} \mathrm{PO} 4,1 \mathrm{mM}$ EDTA, $\mathrm{pH}$ adjusted to 3.0 with $\mathrm{H}_{3} \mathrm{PO}_{4}$; (C) extracting solution $3 \% \mathrm{MPA}$, $8 \%$ acetic acid, $0.3 \mathrm{~N}_{2} \mathrm{SO}_{4}$ and $1 \mathrm{mM} \mathrm{EDTA}$, mobile phase $1 \mathrm{mM} \mathrm{NaH} \mathrm{H}_{2} \mathrm{PO}$, $1 \mathrm{mM}$ EDTA, $\mathrm{pH}$ adjusted to 3.0 with $\mathrm{H}_{3} \mathrm{PO}_{4}$

To overcome this problem and maintain MPA because it is considered one of the best acids for AA preservation, ${ }^{1}$ extracting solution was prepared with a lower MPA (3\%) concentration and the $\mathrm{pH}$ in the mobile phase was raised from 2.2 to 3.0, using $\mathrm{H}_{3} \mathrm{PO}_{4}$ instead of MPA to adjust the $\mathrm{pH}$. These measures were based on the fact that $\mathrm{H}_{3} \mathrm{PO}_{4}$ has a lower tendency to crystallization than MPA and a very low $\mathrm{pH}$ could damage the durability of the reverse phase column. However, with the alteration in the mobile phase, the AA peak resolution became very poor, as shown in Figure 2B). Once again, the extracting solution was modified to a mixture containing MPA, acetic acid, sulfuric acid and EDTA. In this case there was no loss in extraction efficiency and the peak resolution improved considerably with the use of these conditions (Figure $2 \mathrm{C}$ ).

\section{Optimization of the DHA reduction process}

Different DTT concentrations and several reaction times were tested to reduce the DHA present in the samples. The addition of 1 $\mathrm{mL}$ DTT (4 or $8 \mathrm{mM}$ ) to $1 \mathrm{~mL}$ of collard and tomato extract, containing 4.5\% MPA, resulted in AA loss or increases of at most $4 \%$, after reaction times of 75, 90 and $120 \mathrm{~min}$, as proposed by Gökmen et al. ${ }^{6}$ Thus it was attempted to increase the DTT concentration, using a solution at $50 \mathrm{mM}$, but the results did not change.

The DTT action was very low at the $\mathrm{pH}$ of the extracting solutions containing MPA (1.5 to 2.0), and it was necessary to raise the $\mathrm{pH}$ of the extracts before their addition, because DTT act better at a $\mathrm{pH}$ close to neutrality. ${ }^{25}$ For this, 0.5 to $1.5 \mathrm{~mL}$ Trizma buffer $0.5 \mathrm{M}$, pH 9.0 was used, to obtain a final $\mathrm{pH}$ between 5.5 and 6.0. An even greater rise in the $\mathrm{pH}$ was avoided because the AA stability $\mathrm{pH}$ range is 4-6. ${ }^{26}$ It was chosen to use the Trizma buffer ( $\mathrm{pH} 9.0$ ) because at the volume used the phosphate buffer ( $\mathrm{pH}$ 7.0) was not sufficient to raise the extract $\mathrm{pH}$.

The reduction in the extract $\mathrm{pH}$ before injection was shown not to be necessary, when a mobile phase acidified with MPA, $\mathrm{pH}$ 2.2, was used, because AA was stable in solution at pH 6.0 after 15 min, shown in Figure 3. It is possible that the ascorbate oxidase may have been inactivated during extraction using MPA, which did not allow the enzyme to act again after the $\mathrm{pH}$ returned to 6.0 during the DTT reaction time.

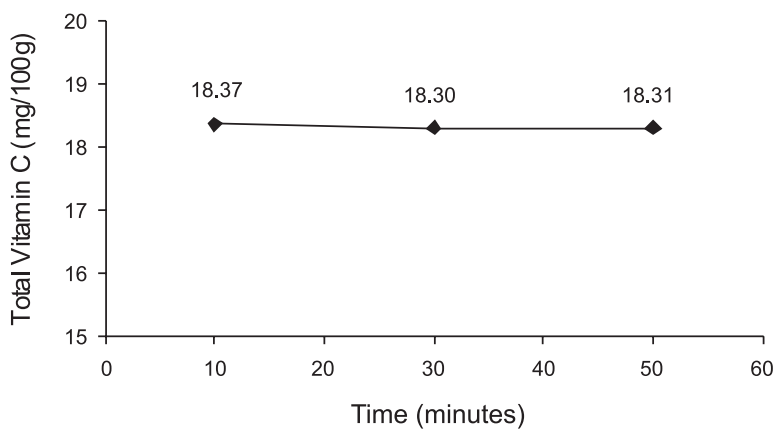

Figure 3. Vitamin C contents $(\mathrm{mg} / 100 \mathrm{~g})$ in tomato, extracted with $4.5 \% \mathrm{MPA}$, after 10, 30 and 50 min reaction with dithiothreitol and Trizma buffer.

However, as the chromatography conditions and the extracting solution had to be altered, as already reported, the way of using DTT also had to be modified. The injection of samples with DTT and Trizma buffer at the mobile phase containing $\mathrm{NaH}_{2} \mathrm{PO}_{4}$, EDTA and $\mathrm{H}_{3} \mathrm{PO}_{4}$ was not successful, because the AA peak was not detected. To overcome this situation, it was necessary to reduce the $\mathrm{pH}$ of the solution before injection, with $0.4 \mathrm{M} \mathrm{H}_{2} \mathrm{SO}_{4}$.

The Trizma buffer solution was used to neutralize the $\mathrm{pH}$ of the extract and it was then added of DTT solutions at 10 and $50 \mathrm{mM}$. The quantity of DTT necessary depended on the DHA content present 
in the sample. Based on reports from other authors ${ }^{5,6}$ and on tests it was concluded that the use of $50 \mathrm{mM}$ DTT did not result in greater conversion than when $10 \mathrm{mM}$ were used. Therefore a $40 \mathrm{mM}$ DTT solution was used diluted in the buffer itself. When the DTT solution and buffer were mixed with the sample the final DTT concentration was $20 \mathrm{mM}$. That is, $1 \mathrm{~mL}$ of the extract was added to $1 \mathrm{~mL}$ buffer solution containing $40 \mathrm{mM}$ DTT that resulted in solution where the DTT was diluted to $20 \mathrm{mM}$.

Similarly, a long reaction time was not needed. The use of $20 \mathrm{mM}$ DTT required 10 min reaction. There was no difference in the DHA conversion when the reaction time was doubled to $20 \mathrm{~min}$.

The DHA was then converted in the following manner: $1 \mathrm{~mL}$ Trizma buffer $0.5 \mathrm{M}$ (pH 9.0) containing $40 \mathrm{mM}$ DTT was added to 1 $\mathrm{mL}$ sample. After $10 \mathrm{~min}$ reaction, at room temperature and protected from the light, the process was interrupted by adding $0.5 \mathrm{~mL} 0.4 \mathrm{M}$ $\mathrm{H}_{2} \mathrm{SO}_{4}$, obtaining a final $\mathrm{pH}$ close to 2 , and the injection was made immediately afterwards.

\section{Extraction and analysis in collards with oil}

To verify the influence of the presence of oil in vitamin C extraction and analysis, similar collard samples were analyzed parallely in the natural form and with the addition of oil. The heat treatment (stir frying) was not applied to the collard samples with oil so as not to confuse the influence of oil presence and losses caused by heat. Extraction, DHA conversion and chromatographic analysis were carried out according to the optimized methodology reported previously in this study. The only adjustment needed was in the Trizma buffer and $\mathrm{H}_{2} \mathrm{SO}_{4}$ volumes added: $1.5 \mathrm{~mL}$ Trizma buffer containing $40 \mathrm{mM}$ DTT, to attain $\mathrm{pH}$ close to 5.5. Sulfuric acid $\left(\mathrm{H}_{2} \mathrm{SO}_{4}\right.$ was added to reduce the $\mathrm{pH}$ before injection: $1.5 \mathrm{~mL} 0.4 \mathrm{M} \mathrm{H}_{2} \mathrm{SO}_{4}$.

It was observed that the addition of oil did not influence vitamin $\mathrm{C}$ extraction and DHA conversion. The mean variation coefficient of the AA contents in the samples with and without oil was $1.53 \%$. AA recovery from collards with oil was $95.5 \%$ (mean of three replications). Thus it can be stated that the method optimized here can be used to analyze stir fried collards.

\section{Validation of the methodology}

The standard curve was constructed with 5 points, each point in triplicate. The concentration ranges were $16.5-206.1 \mu \mathrm{g} / \mathrm{mL}$ and the purity of standard solution was $97 \%$. The real concentration was calculated using coefficient of molar absorptivity of 560 , at $245 \mathrm{~nm}$ and $\mathrm{pH}$ 2.0. The maximum wavelength and coefficient of molar absorptivity depends on the ionic state of the molecule and therefore is influenced by $\mathrm{pH}$ of the medium. ${ }^{27}$ In acid solution the ascorbic acid exists predominantly in unionized form. Within the $\mathrm{pH}$ range of $5-10$, the ascorbic acid is predominantly as an anion. ${ }^{1}$ Bui-Nguyen ${ }^{28}$ presented coefficient of molar absorptivity of 682.88 at $246 \mathrm{~nm}$ (acid solution) and Aldrigue ${ }^{29}$ presented a coefficient of 699.12 at $263 \mathrm{~nm}$, using water as a solvent.

Good linearity was detected, with high determination coefficient $\left(\mathrm{R}^{2}=0.9996\right)$. The detection limit was $50 \mu \mathrm{g} / \mathrm{L}$ determined in relation to a peak whose area was three times greater than the baseline. The repeatability of the method was tested by six consecutive injections of $30 \mu \mathrm{L}$ of standard AA at $50 \mu \mathrm{g} / \mathrm{mL}$. The results in the form of relative standard deviation were $1.70 \%$ for the peak area and $0.59 \%$ for the retention time.

Recovery tests were carried out by adding 0.5 to $1.0 \mathrm{mg}$ AA to the collard and tomato samples. The average recovery was $90 \%$ for the collards (mean of four replications, between 83 and 99\%) and $90 \%$ for the tomatoes (ranging from 85 to $93 \%$ ).

\section{AA and DHA contents in the samples}

Table 1 shows the AA, DHA and total vitamin $\mathrm{C}$ contents in the samples analyzed. About $21 \%$ of total vitamin $\mathrm{C}$ in the collards was detected in the form of DHA and $17 \%$ of total vitamin $\mathrm{C}$ in tomato. These values were different from those reported by Gökmen et al. ${ }^{6}$ where the DHA represented about $41 \%$ of the total vitamin $\mathrm{C}$ of the tomato (7.9 mg/100 g AA and $5.4 \mathrm{mg} / 100 \mathrm{~g} \mathrm{DHA})$. Although they did not analyze collards, these authors reported to not have detected AA in leafy vegetables such as parsley and mint but rather a high DHA content $(218.4 \mathrm{mg} / 100 \mathrm{~g}$ in parsley and $50.3 \mathrm{mg} / 100 \mathrm{~g}$ in mint). These results may have occurred because extraction was performed only with water that may have brought about oxidation of AA to DHA during the extraction process, with reversion after adding DTT. With the breaking of the plant cell structures during extraction, exposure to oxygen was increased and ascorbate oxidase activity may have proceeded freely, because the $\mathrm{pH}$ in the leafy vegetable extracts was close to neutrality.

Table 1. Ascorbic acid (AA), dehydroascorbic acid (DHA) and total vitamin $\mathrm{C}$ contents in vegetables

\begin{tabular}{lccc}
\hline Vegetable & AA $(\mathrm{mg} / 100 \mathrm{~g})$ & DHA $(\mathrm{mg} / 100 \mathrm{~g})$ & Vit C $(\mathrm{mg} / 100 \mathrm{~g})$ \\
\hline Collard & $83.38 \pm 8.67$ & $24.21 \pm 4.94$ & $113.47 \pm 7.92$ \\
Tomato & $16.54 \pm 3.77$ & $3.03 \pm 0.58$ & $17.94 \pm 0.75$ \\
\hline
\end{tabular}

Means of 3 observations \pm standard deviation

In vegetables with low $\mathrm{pH}$, such as tomato, extraction with water seems to less damage the AA, although expressively. In leafy vegetables, extraction without reduction in the $\mathrm{pH}$ led to almost total AA oxidation.

Results similar to the findings of this study were reported by Wills et al. ${ }^{30}$ in tomato, where the DHA represented $7 \%$ of the total vitamin C (18.7 mg/100 g de AA and $1.5 \mathrm{mg} / 100 \mathrm{~g}$ DHA). In another study, that determined DHA after chromatographic separation and detection by fluorimetry, the percentage of DHA in relation to the total vitamin $\mathrm{C}$ contents in tomatoes was only $2.4 \% .^{15}$

Unfortunately, few studies have analyzed DHA in vegetables, restricting the comparison of results. Similarly, few studies were found involving AA analysis in collards by HPLC. The values detected for tomato in the present study were within the range reported by other authors, considering the wide diversity of cultivars available. ${ }^{7,31}$

\section{CONCLUSIONS}

Adding MPA to the extracting solution contributed to AA preservation during the extraction process, and was an indispensable measure in the case of vegetable analysis. However, to improve the repeatability of the method it was necessary to reduce the proportion of MPA and add other acids and EDTA to stabilize AA.

Small quantities of DTT were necessary to convert DHA to AA, but the $\mathrm{pH}$ of the solution should be neutralized so that the reaction proceeds efficiently. The $\mathrm{pH}$ needed to be readjusted to 2.0 before injection.

The methodology proposed here was efficient in extracting AA from vegetables, including leafy vegetables with the addition of oil and was shown to be specific. Although the need to adjust the $\mathrm{pH}$ of the extracts for DHA conversion introduced more steps in the analysis, this resulted in the improvement of the quality of the data obtained.

\section{ACKNOWLEDGMENTS}

The authors thank FAPEMIG for the Master of Science scholarship to the first author. 


\section{REFERENCES}

1. Ball, G. F. M. X.; Water-soluble vitamin assays in human nutrition, Chapman \& Hall: London, 1994.

2. Mahan, L. K.; Escott-Stump, S.; Krause: Alimentos, Nutrição e Dietoterapia, $11^{\text {th }}$ ed., Rocca: São Paulo, 2005.

3. Cardoso, M. A.; Penteado, M. V. C.; Cad. Saúde Pública 1994, 10, 231.

4. Lee, S. K.; Kader, A. A.; Postharvest Biology and Technology 2000, 20, 207.

5. Hernández, Y.; Lobo, M. G.; González, M.; Food Chem. 2006, 96, 654.

6. Gökmen, V.; Kahraman, N.; Ddemir, N.; Acar, J.; J. Chromatogr., A 2000, 881, 309.

7. Frenich Garrido, A.; Hernández Torres, M. E.; Belmonte Vega, A.; Martínez Vidal, J. L.; Plaza Bolaños, P.; J. Agric. Food Chem. 2005, 53 , 7371.

8. Franke, A. A.; Custer, L. J.; Arakaki, C.; Murphy, S. P.; J. Food Comp. Anal. 2004, 17, 1.

9. Giannakourou, M. C.; Taoukis, P. S.; Food Chem. 2003, 83, 33.

10. Burini, G.; J. Chromatogr., A 2007, 1154, 97.

11. Tudela, J. A.; Espín, J. C.; Gil, M. I.; Postharvest Biology and Technology 2002, 26, 75.

12. Kabasakalis, V.; Siopidou, D.; Moshatou, E.; Food Chem. 2000, 70, 325.

13. AOAC; Official methods of analysis of the Association of Official Analytical Chemists, $15^{\text {th }}$ ed., Arlington, VA, 1990.

14. Lisiewska, Z.; Kmiecik, W.; Food Chem. 1996, 57, 261.
15. Kall, M. A.; Andersen, C.; J. Chromatogr., A 1999, 730, 101.

16. O’Connell, P. J.; Gormally, C.; Pravda, M.; Guilbault, G. G.; Anal. Chim. Acta 2001, 431, 239.

17. Versari, A.; Mattioli, A.; Parpinello, G. P.; Galassi, S.; Food Control 2004, 15, 355

18. Herrero-Martínez, J. M.; Simó-Alfonso, E.; Deltoro, V. I.; Calatayud, A.; Ramis-Ramos, G.; Anal. Biochem. 1998, 265, 275.

19. Furusawa, N.; Food Control 2001, 12, 27.

20. Shekhovtsova, T. N.; Muginova, S. V.; Luchinina, J. A.; Galimova, A. Z.; Anal. Chim. Acta 2006, 573-574, 125.

21. Silva, F. O.; Food Control 2005, 16, 55.

22. Sánchez-mata, M. C.; Cámara, M.; Díez-Marqués, C.; Food Chem. 2003, 80,317 .

23. Saari, N.; Osmana, A.; Selamat, J.; Fujita, S.; Food Chem. 1999, 66, 57.

24. Iwase, H.; Talanta 2003, 60, 1011.

25. Okamura, M.; Clin. Chim. Acta 1980, 103, 259.

26. Moser, U.; Bendich, A. Em Handbook of vitamins; Machlin, L. J., ed.; Marcell Dekker: New York, 1991.

27. Karayannis, M. I.; Samios, D. N.; Gousetis, C. P.; Anal. Chim. Acta 1977, 93, 275

28. Bui-Nguyen, M. H.; J. Chromatogr. Sci. 1985, 30, 267.

29. Aldrigue, M. L.; Tese de Doutorado, Universidade Estadual de Campinas, Brasil, 1998.

30. Wills, R. B. H.; Wimalasiri, P.; Greenfield, H.; J. Agric. Food Chem. 1984, 1904, 836.

31. Abushita, A. A.; Daood, H. G.; Biacs, P. A.; J. Agric. Food Chem. 2000, $48,2075$. 